\title{
Análise da eficiência do uso de aeronaves remotamente pilotadas no mapeamento de solo exposto em manguezais urbanos
}

\author{
Assessing the effectiveness of remotely piloted aircraft to map exposed soil in urban \\ mangroves
}

\author{
Otacílio Lopes de Souza da Paz ${ }^{1}$ \\ Sidney Vincent de Paul Vikou ${ }^{2}$ \\ Daiane Maria Pilattis \\ Marianne Oliveira 4 \\ Eduardo Vedor de Paula 5
}

\begin{abstract}
Palavras-chave:
Sensoriamento remoto

Ecossistemas costeiros

Degradação ambiental

Imagens suborbitais

Drone

Resumo

Manguezais são ecossistemas costeiros de grande relevância ecológica. Mesmo com legislações que assegurem sua proteção, diversas atividades antrópicas resultam em degradação e/ou supressão da sua vegetação. Para mensurar e monitorar tal processo, metodologias clássicas são aplicadas utilizando imagens orbitais de média resolução espacial, sendo que os resultados obtidos não são adequados para estudos de degradação e recuperação ambiental em escala de detalhe, como a mensuração de áreas de solo exposto no interior e entorno dos manguezais. O presente estudo tem por objetivo analisar a eficiência de imageamento por aeronaves remotamente pilotadas (RPA) no mapeamento de áreas de solo exposto em manguezais. Foram realizados imageamento com RPA em 22 manguezais urbanos de Paranaguá/Paraná - litoral sul do Brasil. Ortomosaicos foram gerados a partir dos dados coletados e estes foram submetidos à classificação supervisionada. Em seguida, calcularam-se índices de exatidão global, índice Kappa e erros de comissão e omissão. A identificação de áreas de solo exposto nas franjas e no interior dos bosques de manguezal, a partir de dados coletados por RPA, se mostrou eficiente visto que o índice de exatidão global foi superior a $96 \%$ em todos os ortomosaicos classificados. O índice Kappa esteve acima de 0,95 em todos os ortomosaicos, indicando uma classificação excelente. Os mapeamentos mostram contraste entre a concentração de áreas de solo exposto nos manguezais analisados, permitindo uma regionalização do padrão de degradação da vegetação em três grupos. Os resultados podem auxiliar documentos de planejamento municipal como a revisão do Plano Diretor de Desenvolvimento Integrado, Plano de Saneamento Básico e o Plano de Regularização Fundiária. Estas informações também poderão dar subsídios para estudos de recuperação da vegetação dos manguezais e fiscalização.
\end{abstract}

\section{Keywords}

Remote sensing

Coastal ecosystems

Environmental degradation

Suborbital images

Drone

\begin{abstract}
Although mangroves are ecologically important coastal ecosystems and laws are in place to ensure their protection, anthropogenic activities continue to cause the degradation and/or suppression of mangrove vegetation. Traditional methods to measure and monitor this process, including the use of medium spatial resolution orbital images, are unsuitable for fine-scale environmental degradation and
\end{abstract}

\footnotetext{
${ }^{1}$ Universidade Federal do Paraná, Curitiba, PR, Brasil. otacilio.paz@gmail.com

${ }^{2}$ Universidade Federal do Paraná, Curitiba, PR, Brasil. viksidney@gmail.com

${ }^{3}$ Universidade Federal do Paraná, Curitiba, PR, Brasil. daianepilatti@ufpr.br

${ }^{4}$ Universidade Federal do Paraná, Curitiba, PR, Brasil. marianne.oliveira@ufpr.br

${ }^{5}$ Universidade Federal do Paraná, Curitiba, PR, Brasil. edugeo@ufpr.br
} 
recovery analyses, including the measurement of degraded areas in and around mangroves. Thus, this study aims to analyze the effectiveness of using images from remotely piloted aircraft (RPA) in the mapping of exposed soil areas in mangroves. Imaging with RPA was performed in 22 urban mangroves in Paranaguá, Paraná State, Brazil. Orthomosaics were generated from the collected data and submitted to supervised classification. We then calculated global accuracy and Kappa indices and commission and omission errors. Based on data from the RPA images, the identification of areas of exposed soil on the margins and interior of mangroves was effective since the global accuracy index was higher than $96 \%$ for all classified orthomosaics and the Kappa index was above 0.95 , indicating excellent classification. The mapping shows different concentrations of exposed soil areas in the analyzed mangroves, enabling us to identify three regional patterns of vegetation degradation. The results can inform municipal planning, including revisions to the Integrated Development Master Plan, Basic Sanitation Plan, and Land Regularization Plan. This information may also be used in studies on the recovery and monitoring of mangrove vegetation.

\section{INTRODUÇÃO}

O manguezal é um ecossistema costeiro composto por um conjunto de espécies arbóreas com semelhanças nas características morfológicas, bioquímicas, fisiológicas e reprodutivas (SCHAEFFER-NOVELLI et al., 2000; KENNISH, 2016). Este ecossistema se encontra em áreas costeiras, na transição entre os ambientes terrestres e marinhos como estuários e baías, em regiões tropicais e subtropicais (OLIVEIRA; TOGNELLA, 2014; KENNISH, 2016).

Os manguezais brasileiros constituem a maior área de manguezal contínua do mundo, acompanhando a linha de costa por aproximadamente $\quad 6.800 \quad \mathrm{~km} \quad$ (KJERVE; LACERDA, 1993). Também na costa, concentrase a maior parte da população brasileira (aproximadamente $72 \%$ da população), cujo desenvolvimento acelerado e sem planejamento territorial apropriado levou a perda de aproximadamente $88 \%$ do Bioma Mata Atlântica, um dos mais biodiversos do mundo (SOSMA, 2021). Este impacto atingiu a fitofisionomia manguezal, eliminando vastas áreas desta vegetação através da expansão urbana, portuária, turística e agroindustrial (VANNUCCI, 2002).

Esta paisagem mista, onde o tecido urbano incorpora o manguezal, dá origem ao termo "manguezais urbanos" (BRANDÃO; GUIMARÃES; TRAVASSOS, 2009), que são caraterizados como áreas de mangue sob forte ação antrópica, afetadas pelo despejo de rejeitos sanitários, industriais e agrícolas, pela pressão do mercado imobiliário, pela proximidade de portos, entre outros (SCHAEFFER-NOVELLI, 1995).

$\mathrm{O}$ resultado do avanço urbano sobre o manguezal é a diminuição dos serviços ecossistêmicos prestados, dentre eles, serviços de provisão (ex.: produção de alimento), de suporte (ex.: ciclagem de nutrientes, conectividade na paisagem, manutenção da biodiversidade, reprodução e abrigo de espécies animais), serviços de regulação (ex.: controle de erosão, anteparo para avanço da maré e controle de inundações, retenção de contaminantes e purificação da água) e, ainda, serviços culturais (recreação, valores de bem-estar, beleza cênica) (DUGAN, 1992; SCHAEFFER-NOVELLI et al., 2005; SCHAEFFER-NOVELLI, 2016; PINHEIRO; TALAMONI, 2018). Vale ressaltar, que frente ao cenário de mudanças climáticas, a perda destes serviços ecossistêmicos pode impactar significativamente as populações vizinhas, imediatamente pela falta dos serviços de regulação e proteção física e, em sequência, pela diminuição e/ou perda de outros serviços.

No Brasil existe um conjunto de legislações que assegura a proteção dos manguezais, a citar: proteção das zonas costeiras na Constituição Federal de 1988, definição dos manguezais como áreas de preservação permanente (APP) na Lei $\mathrm{N}^{\mathrm{o}} 12.651 / 12$ (BRASIL, 2012) e demarcação de manguezais como áreas de Reserva Ecológica na resolução CONAMA $\mathrm{n}^{0}$ 004/85. No entanto, mesmo com o aparato legal e relevância ecológica, são encontrados na literatura diversos estudos apontando a degradação dos manguezais por diferentes atividades humanas, como deposição de resíduos (SALEH, 2007), desmatamento (DAYALATHA; ALI, 2018), lançamento de efluentes (LEAL et al., 2017; CELERI et al., 2019), carcinicultura (FERNANDES et al., 2018; LIMA; SILVA; CARVALHO, 2019) e avanços da mancha urbana (CANEPARO, 1999; MATIAS; SILVA, 2017; MAIA et al., 2019).

Dentre as ferramentas e metodologias utilizadas para analisar e mensurar a degradação dos manguezais, técnicas de Sensoriamento Remoto (SR) e Sistema de Informações Geográficas (SIG) tem se 
popularizado, devido à rapidez e periodicidade na obtenção de dados e ampla cobertura de área a custo e tempo reduzidos, quando comparados a campanhas de campo tradicionais (AMARAL et al. 2019). O uso de Aeronave Remotamente Pilotada - ARP (popular drone) traz ainda outros benefícios, como portabilidade, acessibilidade, fácil manuseio, custo baixo a moderado e altíssima resolução espacial de imagens (MILLER; ZITER; KOONTZ, 2020). A partir destas, podem ser extraídas informações de área, distribuição, densidade, índices de vegetação e métricas de paisagem (KUENZER et al., 2011; KANNIAH et al., 2015; WANG et al., 2019).

Os primeiros estudos com estas técnicas objetivando mapeamento ou diagnósticos de manguezais foram realizados com imagens orbitais multiespectrais de média resolução espacial (série LANDSAT) ou fotografias aéreas (GIRI et al., 2011). Dados de média resolução espacial fornecem informações para avaliar condições gerais dos manguezais, não sendo viáveis para estudos de degradação e recuperação ambiental em escala de detalhe como, por exemplo, no contato dos manguezais com manchas urbanas. A avaliação da degradação da vegetação dos manguezais, por meio do mapeamento de áreas de solo exposto em grande escala espacial pode subsidiar políticas públicas de planejamento ambiental e ordenamento territorial, especialmente, elencando padrões de supressão vegetal.

Para tal finalidade, podem ser utilizados sensores orbitais ativos de alta resolução espacial (HELD et al., 2003; JIA et al., 2014), sensores orbitais com alta resolução espectral (HELD et al., 2003; CAO et al., 2018) ou sensores ativos (Light Detection And RangingLIDAR, Radio Detection And Ranging RADAR, entre outros) (KRUMME et al., 2015; SALUM et al., 2020). Apesar dessas soluções tecnológicas, o alto custo atrelado pode dificultar ou mesmo inviabilizar tal análise. Uma solução é encontrada no emprego de aeronaves remotamente pilotadas (RPA, do inglês Remotely Piloted Aircraft), que apresentam baixo a moderado custo, comparativamente.

A partir do exposto, este estudo hipotetiza que os dados de altíssima resolução espacial captados por RPA são eficientes na identificação de áreas de solo exposto nas franjas e interiores de bosques de mangue. Assim, objetivou-se analisar a eficiência de aplicação de imageamento por RPA no mapeamento de áreas de solo exposto em manguezais urbanos.

\section{PROCEDIMENTOS METODOLÓGICOS}

Os procedimentos metodológicos foram divididos em etapas (Figura 1). O ponto inicial foi a elaboração de uma base de dados geoespaciais (BDG) para seleção dos manguezais em análise. Após, seguiu-se para etapas de planejamento de imageamento e levantamentos em campo. As últimas etapas focaram no processamento dos dados coletados.

Figura 1 - Síntese dos procedimentos metodológicos da pesquisa.

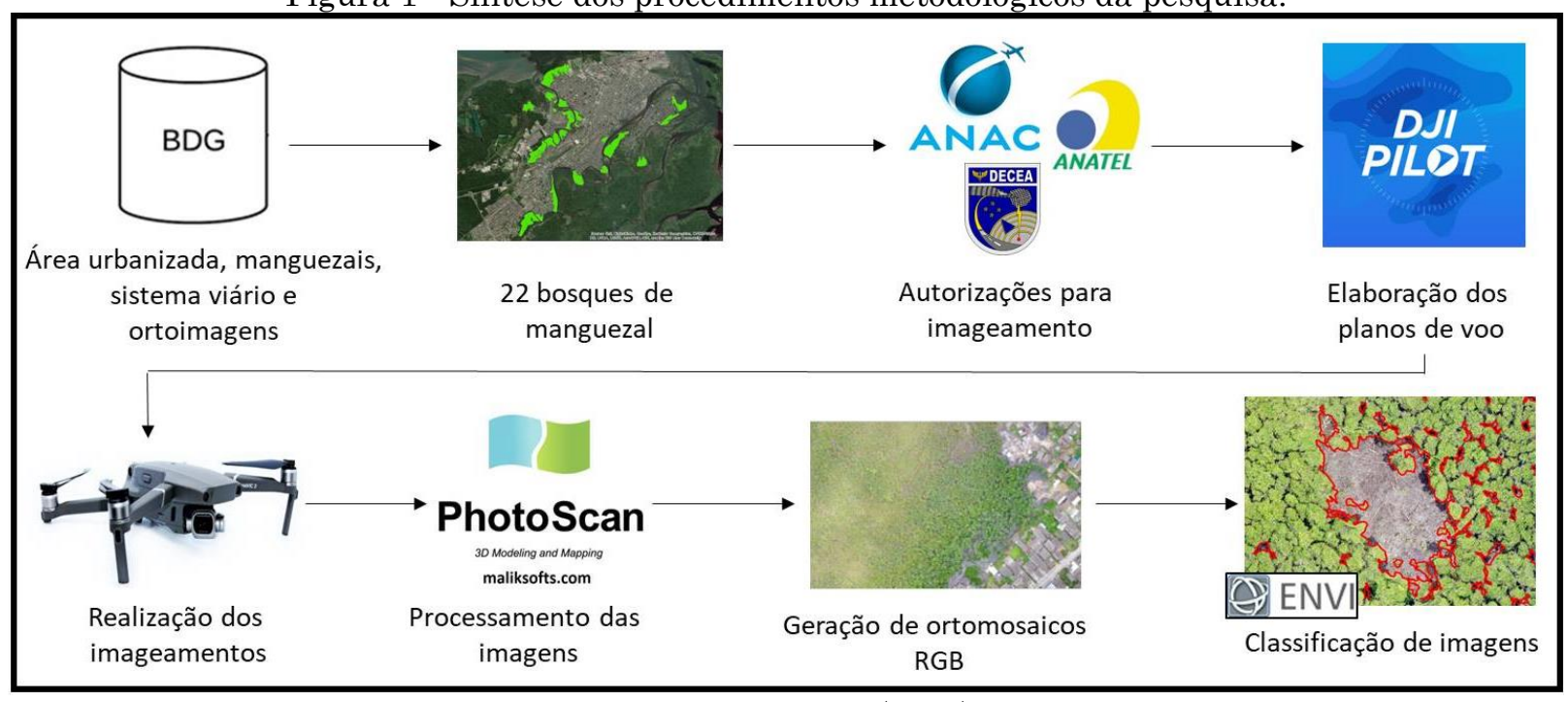

Fonte: Os autores (2021). 
A área de estudo localiza-se no município de

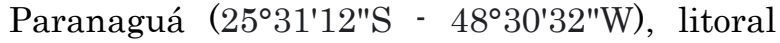
central do Paraná, sul do Brasil (Figura 2). As 22 áreas de manguezais (ou bosques de manguezais) selecionados estão em contato direto com a área urbanizada de Paranaguá. A área total analisada soma 361,36 hectares e se estende nas margens do rio Emboguaçu, rio Itiberê e na ilha dos Valadares, ambos próximos da baía de Paranaguá.

Figura 2 - Localização das áreas de manguezais no entorno da mancha urbana de Paranaguá.

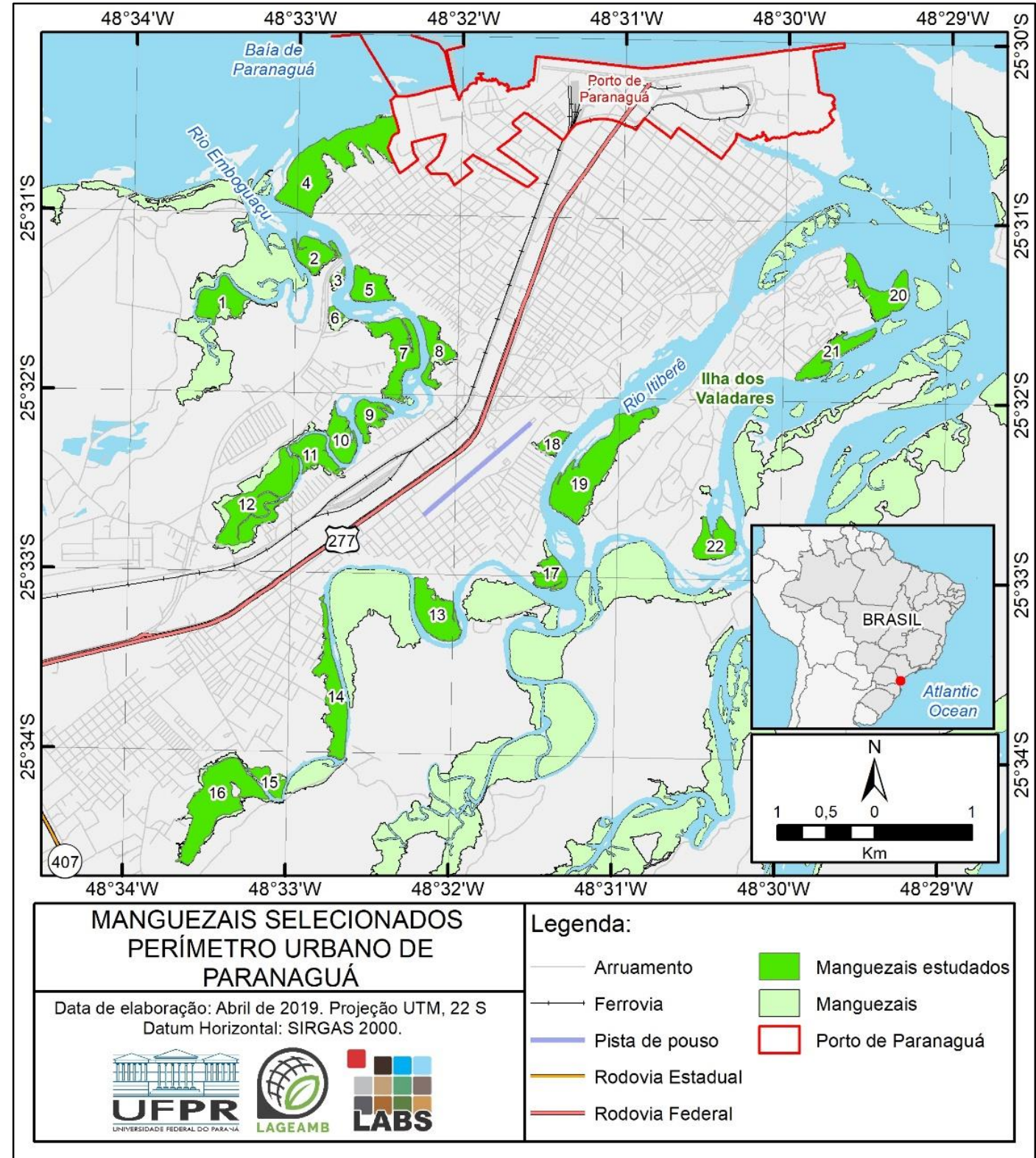

Fonte: Os autores (2021).

Organização de base de dados e seleção de áreas para mapeamento

Foram adquiridos dados geoespaciais secundários publicados pelo Instituto Água e Terra do Paraná (IAT) e pela Secretaria Municipal de Urbanismo (SEMUR) do município de Paranaguá (Quadro 1), dando origem a BDG (PAZ; DAL PAI; PAULA, 2020). As áreas de manguezais escolhidas para imageamento com
RPA foram definidas a partir da ferramenta "selecionar por localização" do QGIS 3.10, empregando como predicado geométrico o parâmetro "tocam", utilizando as camadas "área urbanizada" e "manguezais". Assim, foram selecionadas apenas as áreas de manguezais que estão em contato com a área urbanizada de Paranaguá. Cada área de manguezal selecionada recebeu um identificador numérico simples (Figura 2). 
Quadro 1 - Lista de dados geoespaciais utilizados na pesquisa.

\begin{tabular}{|c|c|c|c|c|}
\hline $\begin{array}{c}\text { Dados } \\
\text { geoespaciais }\end{array}$ & Tipo de dado & Escala/Resolução & Fonte & Aplicação na pesquisa \\
\hline $\begin{array}{c}\text { Área } \\
\text { urbanizada }\end{array}$ & $\begin{array}{c}\text { Levantamento } \\
\text { planialtimétrico - vetorial }\end{array}$ & $1: 10.000$ & IAT (2016) & Seleção de áreas \\
\hline Manguezais & $\begin{array}{c}\text { Levantamento } \\
\text { planialtimétrico - vetorial }\end{array}$ & $1: 10.000$ & IAT (2016) & $\begin{array}{c}\text { Seleção de áreas e planejamento } \\
\text { dos levantamentos }\end{array}$ \\
\hline Pista de pouso & $\begin{array}{c}\text { Levantamento } \\
\text { planialtimétrico - vetorial }\end{array}$ & $1: 10.000$ & IAT (2016) & Planejamento dos levantamentos \\
\hline Sistema viário & $\begin{array}{c}\text { Levantamento } \\
\text { planialtimétrico - vetorial }\end{array}$ & $1: 10.000$ & IAT (2016) & Planejamento dos levantamentos \\
\hline Ortoimagens & $\begin{array}{c}\text { Levantamento cadastral - } \\
\text { matricial }\end{array}$ & 0,2 metro & $\begin{array}{c}\text { SEMUR } \\
(2010)\end{array}$ & $\begin{array}{c}\text { Georreferenciamento dos } \\
\text { ortomosaicos gerados }\end{array}$ \\
\hline
\end{tabular}

Elaboração: Os autores (2021).

Equipamento, planejamento e realização do imageamento

Para obtenção das imagens foi utilizada RPA modelo Mavic 2 Pro, com uma câmera Hasselblad de 20 megapixels. Documentações e autorizações foram solicitadas, atendendo aos requisitos estabelecidos Regulamento Brasileiro de Aviação Civil Especial no 94/2017 (RBAC-E n ${ }^{\circ}$ 94/2017) pela Agência Nacional de Aviação Civil (ANAC), Departamento de Controle do Espaço Aéreo (DECEA) e Agência Nacional de Telecomunicações (ANATEL).

Também foi solicitado acesso ao espaço aéreo no sistema SARPAS - Solicitação de Acesso de Aeronaves Remotamente Pilotadas do Departamento de Controle do Espaço Aéreo (DECEA), sendo apresentadas as áreas a serem imageadas, data e horário de voo, pontos de decolagem, descrição da operação e altura da RPA, definida em 393 pés (cerca de 120 metros).
Foram necessárias cartas de aquiescência assinadas pelos responsáveis do aeroporto de Paranaguá e de um heliponto nas proximidades. Os imageamentos foram realizados nas semanas de 18 a 22 de novembro de 2019 e de 20 a 31 de janeiro de 2019. O intervalo de horário escolhido para captação das imagens foi entre $11 \mathrm{~h}$ e $15 \mathrm{~h}$, com o intuito de evitar sombreamento das folhas pela inclinação da luz do sol.

Os planos de voo foram elaborados no aplicativo DJI Pilot, a partir dos polígonos das áreas de manguezais selecionadas, carregadas no aplicativo em formato Keyhole Markup Language (Kml) (Figura 3). Quando a dimensão da área de manguezal ultrapassava o limite de autonomia da RPA (cerca de 30 hectares - 14 minutos), este era dividido em dois ou três planos de voos (Figura 3). Todos os planos de voo foram realizados com as mesmas características técnicas (Quadro 2).

Figura 3 - Tela do aplicativo DJI Pilot. Exemplo de plano de voo para a primeira parte da área de manguezal 04.

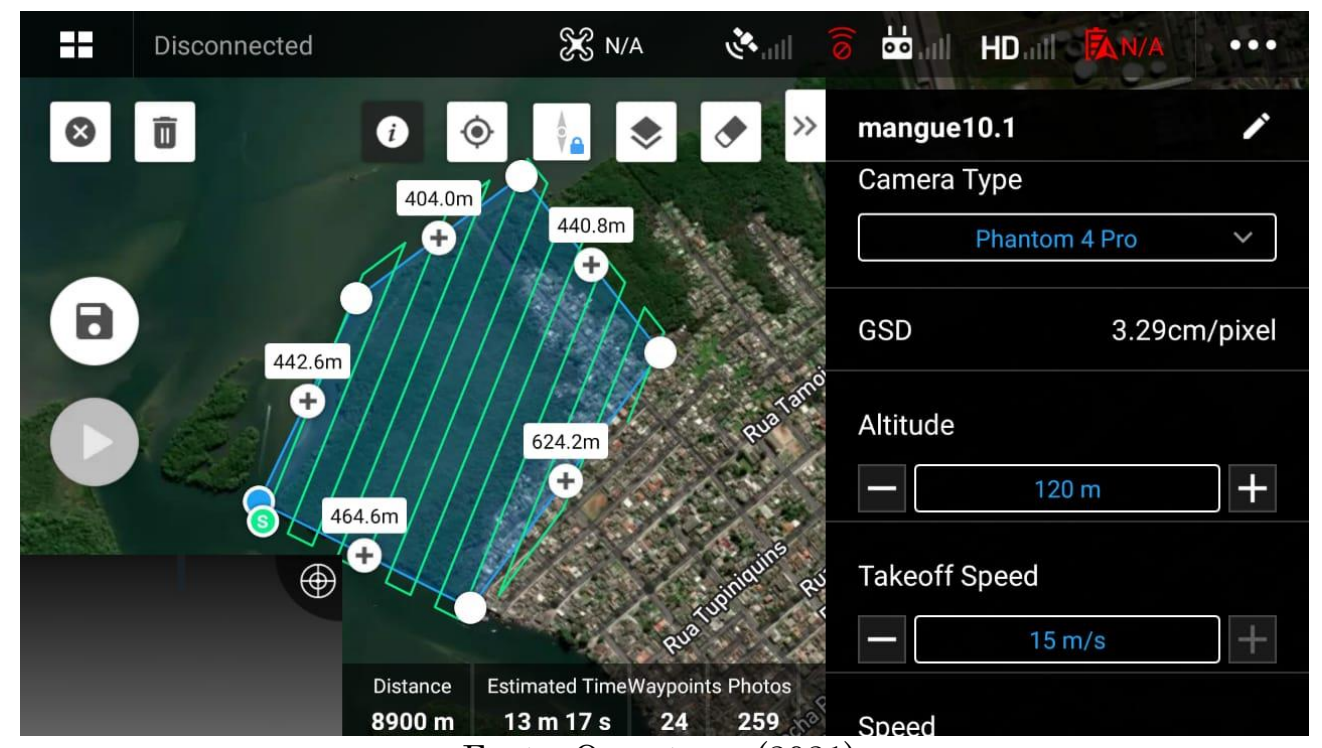

Fonte: Os autores (2021). 
Quadro 2 - Características dos planos de voo elaborados no aplicativo DJI Pilot.

\begin{tabular}{|c|c|l|}
\hline Especificação & Valor/Atributo & \multicolumn{1}{|c|}{ Significado } \\
\hline Camera Type & Phantom 4 Pro & $\begin{array}{l}\text { Tipo de câmera. Na versão do aplicativo utilizada não existia o tipo "Mavic } \\
\text { 2 Pro". Foi selecionado "Phantom 4 Pro" questões de compatibilidade. }\end{array}$ \\
\hline GSD & $3.5 \mathrm{~cm} /$ pixels & $\begin{array}{l}\text { Ground Sample Distance ou distância da amostra do solo. A distância que } \\
\text { o pixel representará do terreno. Relacionado com nível de detalhamento do } \\
\text { imageamento. }\end{array}$ \\
\hline Altitude & $120 \mathrm{metros}$ & Altura da RPA durante o voo. Definido de acordo a legislação. \\
\hline Takeoff Speed & $15 \mathrm{~m} / \mathrm{s}$ & Velocidade de decolagem. \\
\hline Speed & $\begin{array}{c}\mathrm{km} / \mathrm{h} \\
\mathrm{No} / \mathrm{s}\end{array}$ & Velocidade em voo. \\
\hline $\begin{array}{c}\text { Elevation } \\
\text { Optimization }\end{array}$ & No & Utilizado quando o objetivo é a geração de modelos digitais do terreno. \\
\hline Completion & Return to Home & Após o imageamento, a RPA deverá retornar ao ponto de decolagem. \\
\hline $\begin{array}{c}\text { Side Overlap } \\
\text { Ratio (\%) }\end{array}$ & $70 \%$ & Taxa de recobrimento lateral. \\
\hline $\begin{array}{c}\text { Frontal Overlap } \\
\text { Ratio (\%) }\end{array}$ & $70 \%$ & Taxa de recobrimento vertical. \\
\hline Couse angle & Variável & Ângulo que a RPA irá realizar o imageamento. \\
\hline Margin & $30 \mathrm{~m}$ & $\begin{array}{l}\text { Area extra no entorno do polígono carregado. Necessário para evitar efeito } \\
\text { de borda. }\end{array}$ \\
\hline
\end{tabular}

Elaboração: Os autores (2021).

\section{Processamento dos dados coletados e extração de informações}

Após os voos, os dados foram processados no software Agisoft PhotoScan 1.3.3. Seguiu-se o procedimento padrão do software para geração de ortomosaicos, envolvendo alinhamento das imagens, criação de nuvem de pontos, geração de modelo digital de superfície (MDS) e geração de ortomosaico (nuvem de pontos + MDS). O processamento foi executado na qualidade alta (high).

Os ortomosaicos gerados foram exportados com resolução espacial de $0,1 \mathrm{~m}$. O georreferenciamento foi realizado com base nas imagens de maior resolução espacial e melhor qualidade posicional disponível, fornecidas pela SEMUR, com $0,2 \mathrm{~m}$ de resolução espacial, datadas de 2010 e compatíveis no Padrão A da escala 1:10.000 da PEC-PCD (DSG, 2016). Foram utilizados seis pontos de controle em cada ortomosaico, apresentando um erro médio quadrático de $0,9 \mathrm{~m}$. A baixa densidade de pontos de controle se deve à dificuldade de identificação de pontos homólogos e pelas diferenças de resolução espacial entre a imagem base para o georreferenciamento e os ortomosaicos gerados.

Para mapear as áreas de solo exposto nas imagens coletadas foi utilizado o software ENVI 5.3. Realizou-se uma classificação supervisionada pelo algoritmo de máxima verossimilhança (Maximum Likelihood Classification) para as classes "vegetação" e "solo exposto". Foram coletadas 5.000 amostras (pixels) para cada classe a partir da inspeção visual dos ortomosaicos. Este valor foi arbitrado considerando a alta resolução espacial dos dados. Foram selecionados pixels que representassem a variação dos níveis de cinza das bandas do ortomosaico gerado (RGB). As áreas de seleção das amostras foram distribuídas no ortomosaico para evitar a concentração de dados em um único quadrante.

Posteriormente a classificação, foram calculados os índices de exatidão global e Kappa e os erros de comissão e omissão. Tais parâmetros foram calculados no ENVI 5.3 a partir das matrizes resultantes da classificação supervisionada. Os arquivos em formato matricial resultantes da classificação foram convertidos para o formato vetorial (shapefile) no QGIS 3.10. Por fim, foram realizados cálculos de área das classes de solo exposto e vegetação.

\section{RESULTADOS E DISCUSSÃO}

Em função do elevado número de áreas de manguezais analisadas, as ilustrações dos resultados obtidos serão apresentadas a partir de exemplos. Constata-se por meio de análise dos histogramas das amostras selecionadas que a banda do vermelho (Layer_3) é a que melhor distingue às classes "vegetação" e "solo exposto" (Figura 4). Tal fato também é evidenciado ao analisar visualmente cada uma das bandas do ortomosaico da área de manguezal 07 (Figura 4). 
Figura 4 - Exemplo de histogramas de amostras coletadas para classificação dos ortomosaico do manguezal 07. Abaixo dos histogramas, visualização individual das bandas que compõe o ortomosaico (Layer_1: Azul; Layer_2: verde; Layer_3: vermelho).
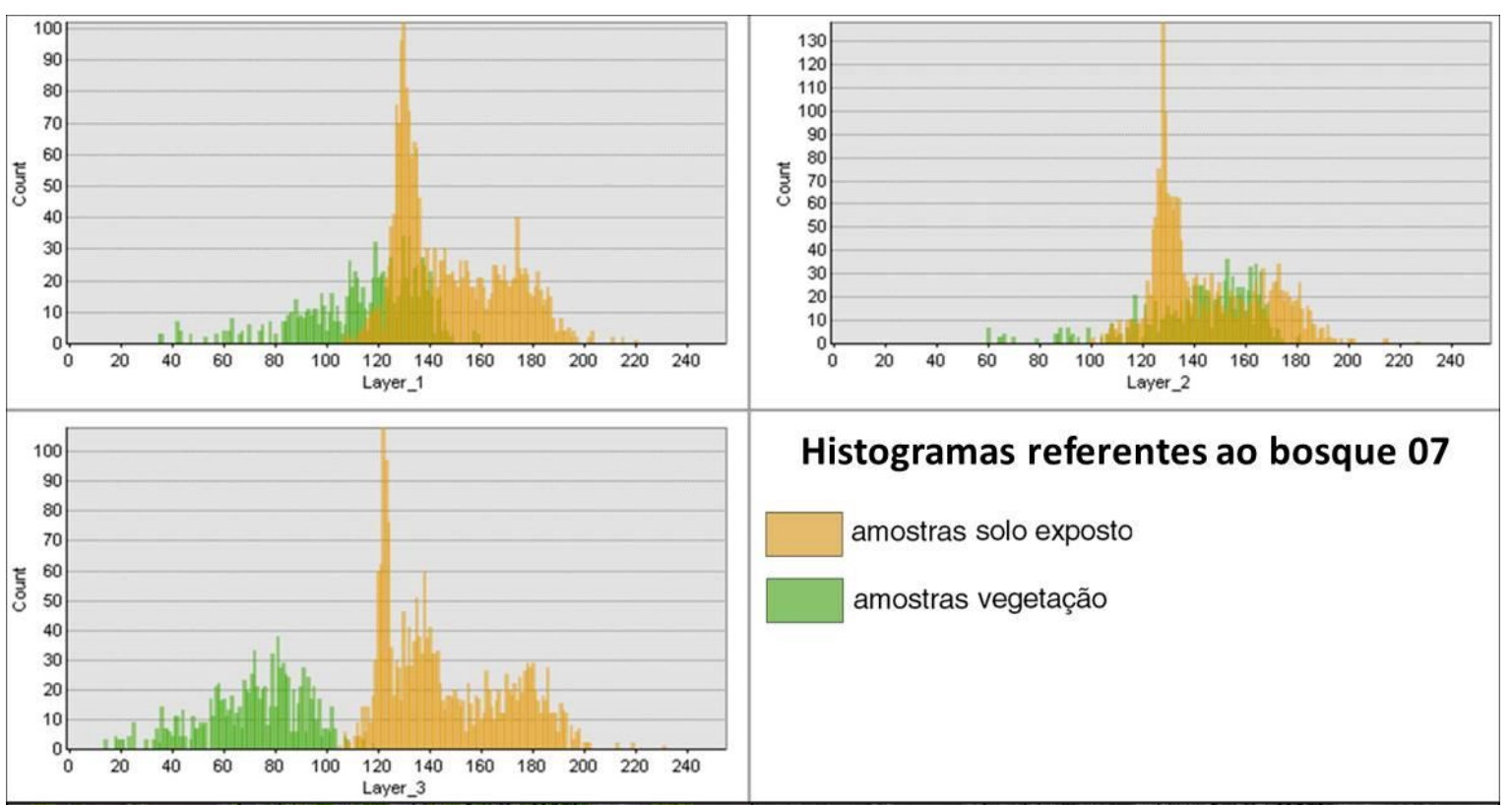

\section{Histogramas referentes ao bosque 07}

$$
\begin{aligned}
& \square \text { amostras solo exposto } \\
& \square \text { amostras vegetação }
\end{aligned}
$$

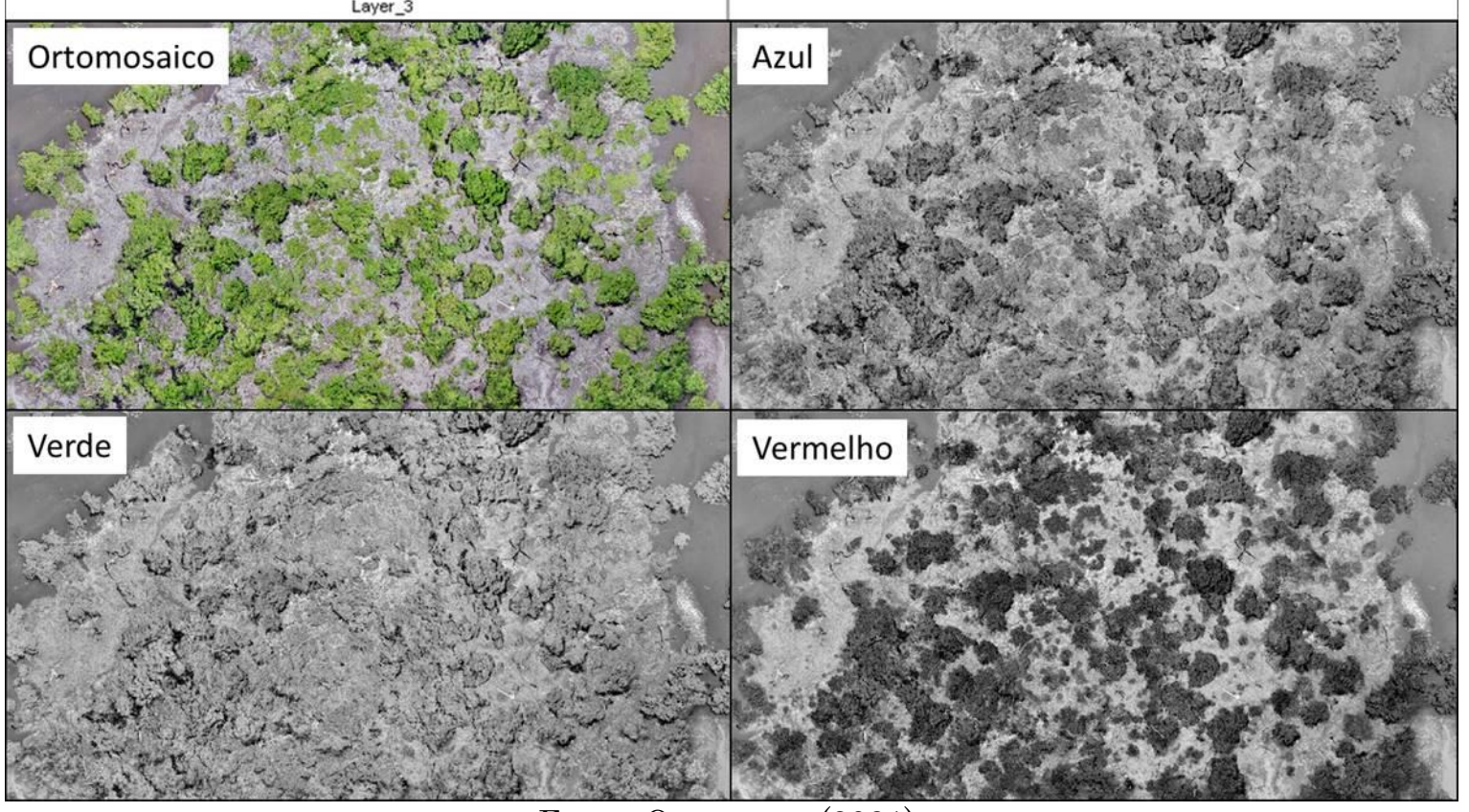

Fonte: Os autores (2021).

O índice de exatidão global foi superior a $96,29 \%$ em todos os ortomosaicos gerados, atingindo um máximo de $98,98 \%$ na área de manguezal 17 (Quadro 3). Quanto ao índice Kappa, todos os resultados ficaram acima de 0,95, indicando uma classificação excelente (Quadro 3) (LANDIS; KOCH, 1977). Uma justificativa para os menores valores de exatidão global e índice Kappa pode ser atribuída a presença de nuvens nos ortomosaicos. Os erros de comissão e omissão em todas as classificações não ultrapassou 5,07\%, indicando uma classificação eficiente. 
Quadro 3 - Índices de exatidão global, índice Kappa e erros de comissão e omissão para a classe de solo exposto.

\begin{tabular}{|c|c|c|c|c|}
\hline $\begin{array}{c}\text { Área de } \\
\text { manguezal }\end{array}$ & $\begin{array}{l}\text { Índice de exatidão } \\
\text { global (\%) }\end{array}$ & Índice Kappa & $\begin{array}{c}\text { Erros de } \\
\text { comissão classe } \\
\text { solo exposto (\%) }\end{array}$ & $\begin{array}{c}\text { Erros de omissão } \\
\text { classe solo } \\
\text { exposto (\%) }\end{array}$ \\
\hline 1 & 97,54 & 0,97 & 3,12 & 3,12 \\
\hline 2 & 96,41 & 0,95 & 3,58 & 3,58 \\
\hline 3 & 97,33 & 0,97 & 3,09 & 3,09 \\
\hline 4 & 97,27 & 0,96 & 3,08 & 3,08 \\
\hline 5 & 98,12 & 0,97 & 3,04 & 3,04 \\
\hline 6 & 96,29 & 0,95 & 5,07 & 5,07 \\
\hline 7 & 97,44 & 0,97 & 3,15 & 3,15 \\
\hline 8 & 97,21 & 0,96 & 3,11 & 3,11 \\
\hline 9 & 97,59 & 0,96 & 3,19 & 3,19 \\
\hline 10 & 97,01 & 0,96 & 3,26 & 3,26 \\
\hline 11 & 97,59 & 0,96 & 3,19 & 3,19 \\
\hline 12 & 98,58 & 0,97 & 3,05 & 3,05 \\
\hline 13 & 98,44 & 0,97 & 3,06 & 3,06 \\
\hline 14 & 96,78 & 0,95 & 4,38 & 4,38 \\
\hline 15 & 98,19 & 0,97 & 3,06 & 3,06 \\
\hline 16 & 98,13 & 0,97 & 3,06 & 3,06 \\
\hline 17 & 98,98 & 0,98 & 3,02 & 3,02 \\
\hline 18 & 97,89 & 0,96 & 3,16 & 3,16 \\
\hline 19 & 97,51 & 0,97 & 3,17 & 3,17 \\
\hline 20 & 98,35 & 0,97 & 3,07 & 3,07 \\
\hline 21 & 98,69 & 0,98 & 3,04 & 3,04 \\
\hline 22 & 96,34 & 0,98 & 4,64 & 4,64 \\
\hline
\end{tabular}

Elaboração: Os autores (2021).

As 22 áreas de manguezais analisadas apresentam em média 4,1 hectares de solo exposto. Na maioria dos casos, a área de solo exposto identificada se concentra nas franjas dos bosques de mangue. Expressivas diferenças de concentração de áreas de solo exposto são visualizadas quando se compara os bosques de mangue (Figura 5). A área de manguezal 07 se destaca com maior concentração de áreas de solo exposto (57,1\%). Em contrapartida, a área de manguezal 21 ganha destaque por apresentar os menores valores de área de solo exposto $(5,53 \%)$ $\mathrm{e}$, consequentemente, maior densidade de vegetação. 
Figura 5 - Comparação da concentração de áreas de solo exposto entre as áreas de manguezais 07 (A) e 21 (B) e tabulação dos percentuais de solo exposto e vegetação nos bosques de manguezais analisadas.

\begin{tabular}{|c|c|c|c|c|c|}
\hline 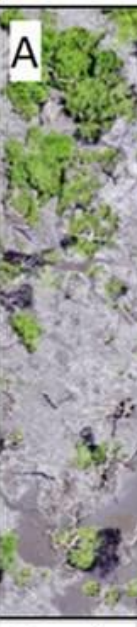 & 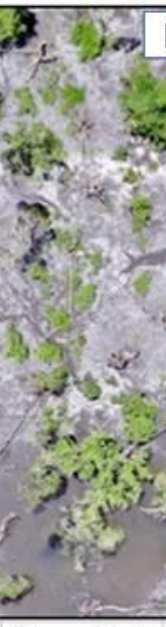 & 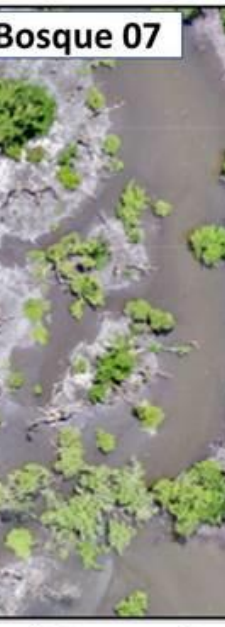 & 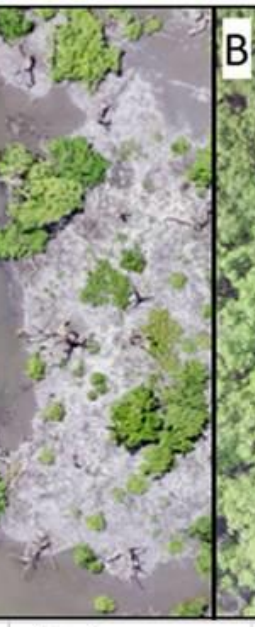 & 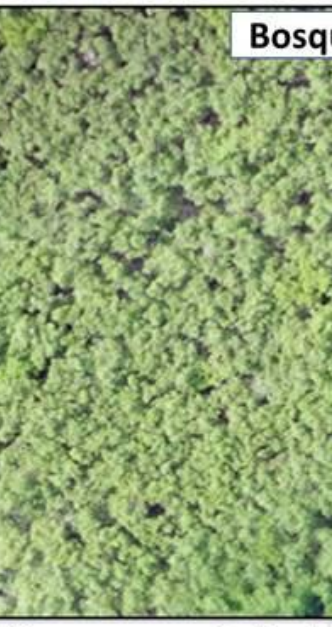 & 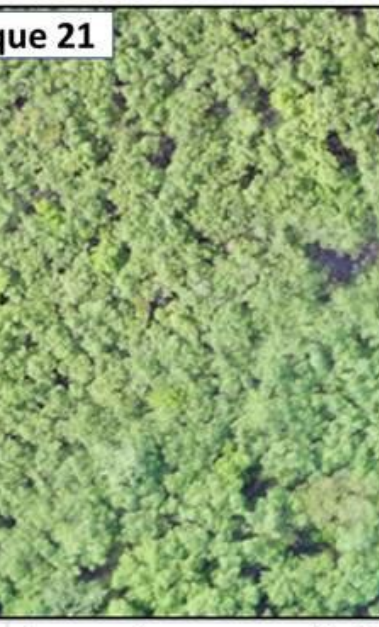 \\
\hline Mancha & Área (ha) & \% Vegetação & $\%$ Solo exposto & Área vegetação (ha) & Área solo exposto (ha) \\
\hline 21 & 13,32 & 94,47 & 5,53 & 12,58 & 0,74 \\
\hline 4 & 46,39 & 90,46 & 9,54 & 42,07 & 4,32 \\
\hline 20 & 17,82 & 89,19 & 10,81 & 15,89 & 1,93 \\
\hline 14 & 21,45 & 87,69 & 12,31 & 18,81 & 2,64 \\
\hline 16 & 37,76 & 87,27 & 12,73 & 32,95 & 4,81 \\
\hline 19 & 38,59 & 83,77 & 16,23 & 32,33 & 6,26 \\
\hline 15 & 6,05 & 74,37 & 25,63 & 4,5 & 1,55 \\
\hline 13 & 18,88 & 74,31 & 25,69 & 14,03 & 4,85 \\
\hline 17 & 8,04 & 73,3 & 26,7 & 5,72 & 2,32 \\
\hline 2 & 10,95 & 72,21 & 27,79 & 7,91 & 3,04 \\
\hline 18 & 4,62 & 69,24 & 30,76 & 3,2 & 1,42 \\
\hline 3 & 1,49 & 67,92 & 32,08 & 1,01 & 0,48 \\
\hline 6 & 2,01 & 67,42 & 32,58 & 1,35 & 0,66 \\
\hline 22 & 13,28 & 66,32 & 33,68 & 8,81 & 4,47 \\
\hline 1 & 14,06 & 65,44 & 34,56 & 9,2 & 4,86 \\
\hline 10 & 10,84 & 65,42 & 34,58 & 7,09 & 3,75 \\
\hline 5 & 11,03 & 64,31 & 35,69 & 7,09 & 3,94 \\
\hline 11 & 11,61 & 60,8 & 39,2 & 7,06 & 4,55 \\
\hline 12 & 33,64 & 60,26 & 39,74 & 20,27 & 13,37 \\
\hline 9 & 9,03 & 55,8 & 44,2 & 5,04 & 3,99 \\
\hline 8 & 10,21 & 47,26 & 52,74 & 4,89 & 5,32 \\
\hline 7 & 20,3 & 45,9 & 54,1 & 9,32 & 10,98 \\
\hline
\end{tabular}

Fonte: Os autores (2021).

Exemplo do mapeamento executado é apresentado para a área de manguezal 13 (Figura 6). Utilizando como critérios a proporção elevada de valores de porcentagem de solo exposto e a posição geográfica, propõe-se a regionalização das áreas de manguezais analisadas em três grupos: A) manguezais nas margens do rio Emboguaçu; B) manguezais nas margens do rio Itiberê; C) manguezais na ilha dos Valadares (Figura 7). 
Figura 6 - Exemplo de mapeamento de solo exposto na área de manguezal 13.

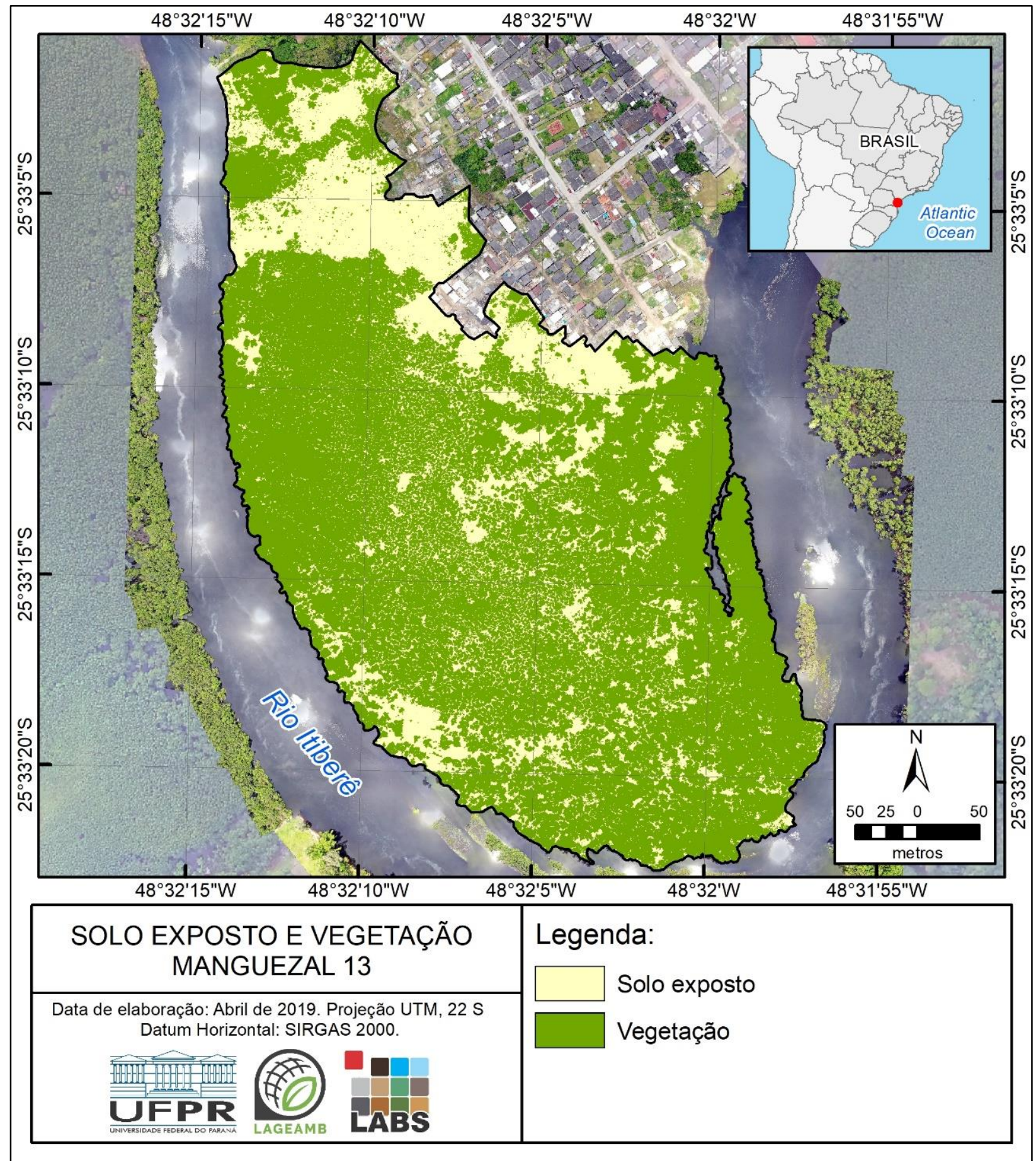

Fonte: Os autores (2021). 
Figura 7 - Regionalização das áreas de manguezais analisadas no estudo. Critérios: proporção de valores de solo exposto e a localização geográfica.

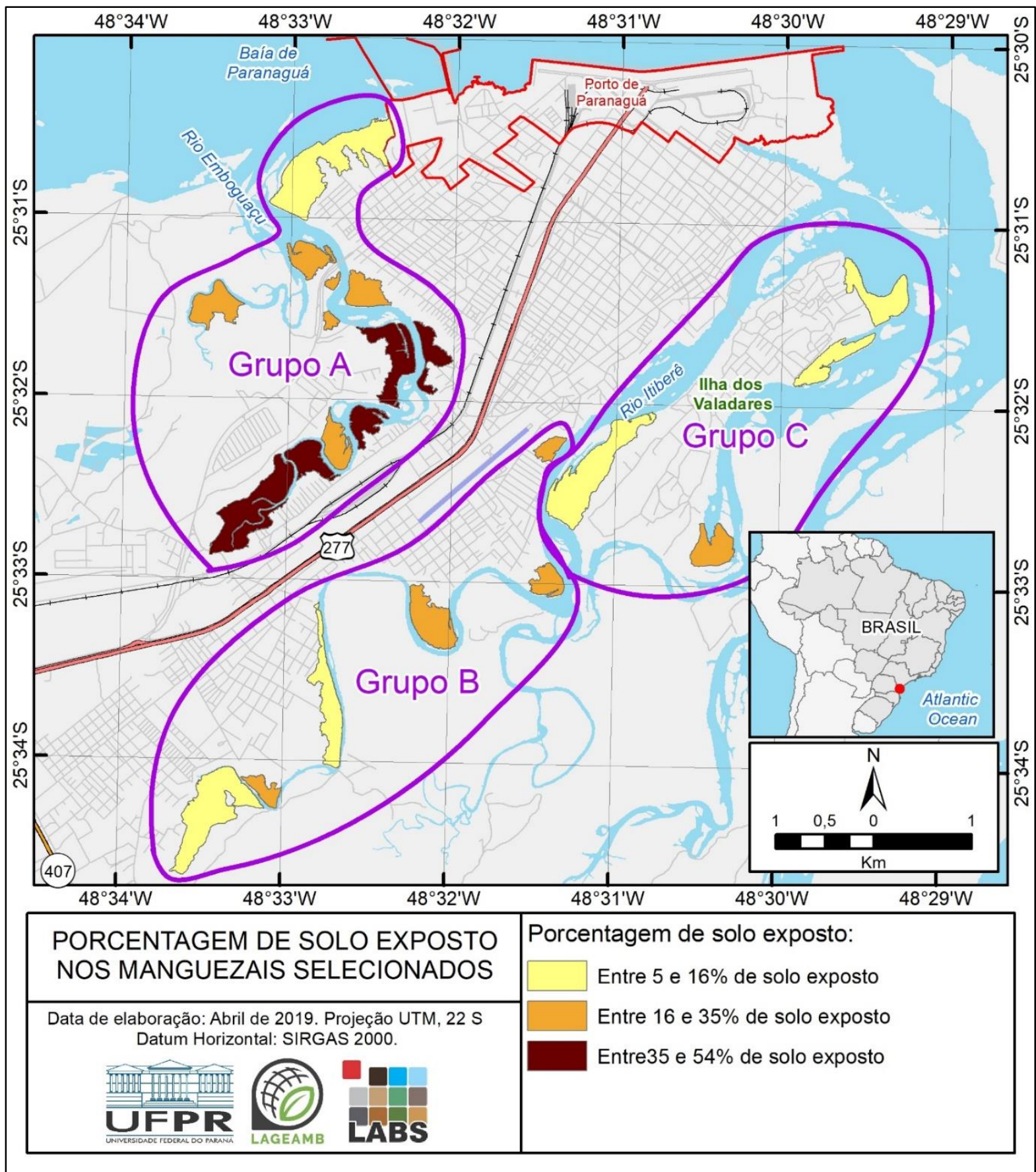

Fonte: Os autores (2021).

Em termos proporcionais, manguezais com elevadas proporções de solo exposto ocorrem na margem do rio Emboguaçu (Grupo A), enquanto manguezais com maior proporção de áreas de vegetação estão no Grupo C. Os manguezais do grupo B apresentam valores de solo exposto e vegetação intermediários. A Figura 8 apresenta uma comparação com imagens oblíquas da área de manguezal 08, inserida no grupo A, e da área de manguezal 19, inserida no grupo C. 
Figura 8 - Imagens obliquas registradas com a RPA. Altura aproximada: 80 metros. Coordenadas aproximadas da RPA no momento de registro das imagens: A) $25^{\circ} 31^{\prime} 42.26^{\prime \prime} \mathrm{S}$ e $48^{\circ} 32^{\prime} 33.10^{\prime \prime} \mathrm{W}$. B) $25^{\circ} 31^{\prime} 43.57^{\prime \prime S}$ e $48^{\circ} 29^{\prime} 48.49^{\prime \prime} \mathrm{W}$.

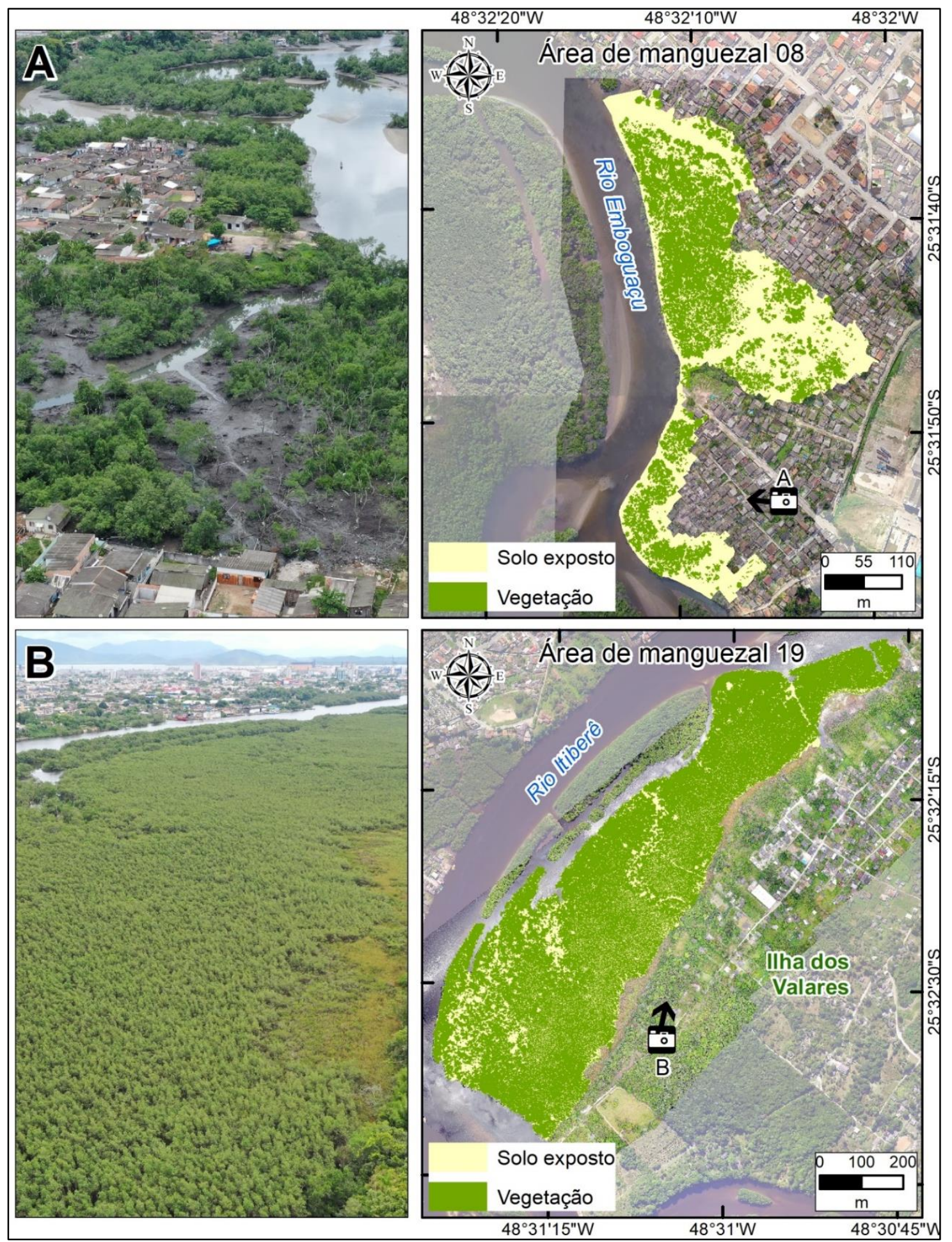

Fonte: Os autores (2021).

Além de indicar o nível de degradação de um manguezal, áreas de solo exposto podem indicar espaços aptos à recuperação da vegetação. Neste contexto a área de manguezal 07 apresentou os maiores valores de solo exposto. De acordo com imagens do acervo Google Earth, o referido manguezal apresentava expressiva área de solo exposto em outubro de 2002, situação revertida ao se observar a imagem de abril de 2013, onde a área de solo exposto estava ocupada por vegetação de manguezal (Figura 9). 
Figura 9 - Evolução espacial e temporal da área de manguezal 07 entre 2002 e 2017. Coordenadas aproximadas do centro das imagens: 25³1'42.57"S e 48³2'19.59"O. Escala aproximada: 1:2.500.

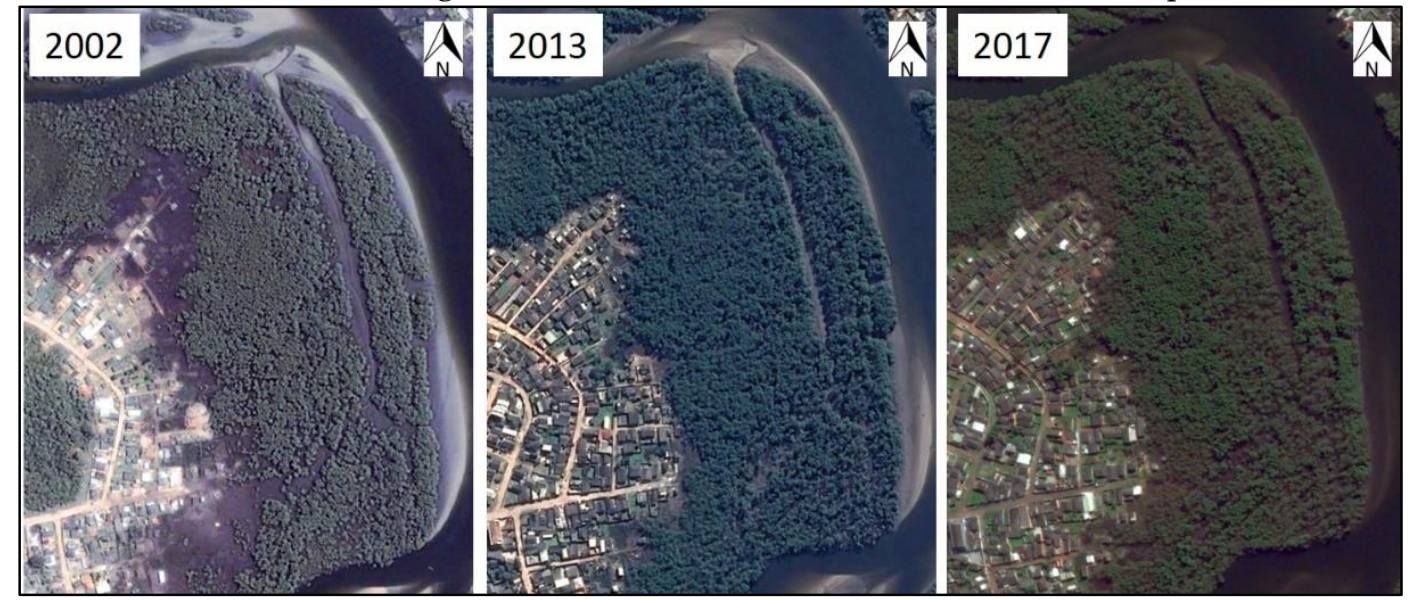

Fonte: Acervo Google Earth (2021).

Avaliando a variação da vegetação ao longo das últimas décadas no manguezal da área de manguezal 07 (Figura 9 e Figura 10), nota-se que após 2002, a área urbana não cresceu ao ponto de justificar a mortandade de novos indivíduos de mangue. Provavelmente, em 2002, a área de solo exposto adjacente a matriz urbana tenha se originado de práticas para a projeção do arruamento, como supressão vegetal, seguida de aterramento do manguezal (sugere-se análise histórica do processo de ocupação dessas áreas).

Porém, entre 2013 e 2017, a mesma área apresentou regeneração natural significativa. A regeneração natural de manguezais está relacionada a diferentes fatores, dentre eles a distribuição espacial das plântulas, características dos propágulos, padrão de colonização de cada espécie, características edáficas (como salinidade e teor de matéria orgânica), densidade e composição de outras espécies de mangue, influência da maré, herbivoria, entre outros (PELOZO, 2012; MADI et al., 2016). Sendo assim, diversos fatores naturais podem justificar a regeneração desta área, além da possibilidade indireta de retirada de estressores abióticos, como despejo de poluentes ou resíduos sólidos (diferentes fontes de lixo doméstico).

Figura 10 - Foco no setor norte da área de manguezal 07.
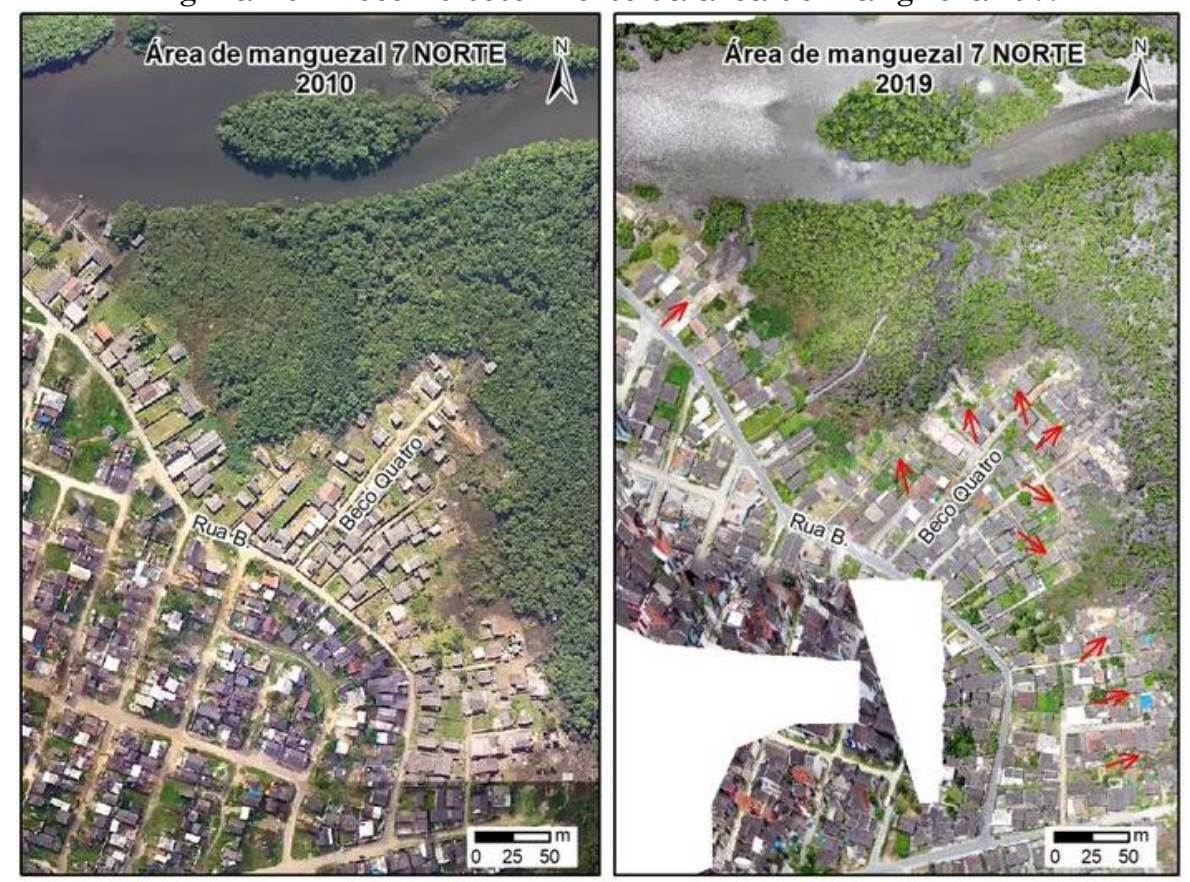

Fonte: Imagem 2010 - SEMUR (2010). Imagem 2019 - Os autores (2021). 
Entretanto, em 2019 inicia-se um novo processo de degradação, sem associação com expansão da área da urbana, que pode estar relacionada com a presença ou não de poluentes no solo, maior sedimentação ao longo do rio, devido a eventos naturais ou não (ex.: construção de barragens artificiais ao longo do rio, através do depósito de pneus, lixo domiciliar e entulhos), ou ainda, em resposta a fatores naturais já citados, como herbivoria. Recomenda-se investigação in loco dos possíveis fatores de degradação destes manguezais.
A partir da alta resolução espacial propiciada pelas imagens da RPA é possível identificar elementos como árvores mortas, áreas com lixo, caminhos para barcos, loteamentos e lançamento de resíduos sólidos e líquidos (Figura11). Tanto áreas de solo exposto como a presença destes elementos podem indicar o grau de degradação das áreas de manguezais, corroborando com ideias já apresentadas em estudos anteriores (CANEPARO, 1999; CANEPARO, 2000; GIRI et al., 2011; KANNIAH et al., 2015; CELERI et al., 2019).

Figura 11 - Demais elementos encontrados nos ortomosaicos gerados.

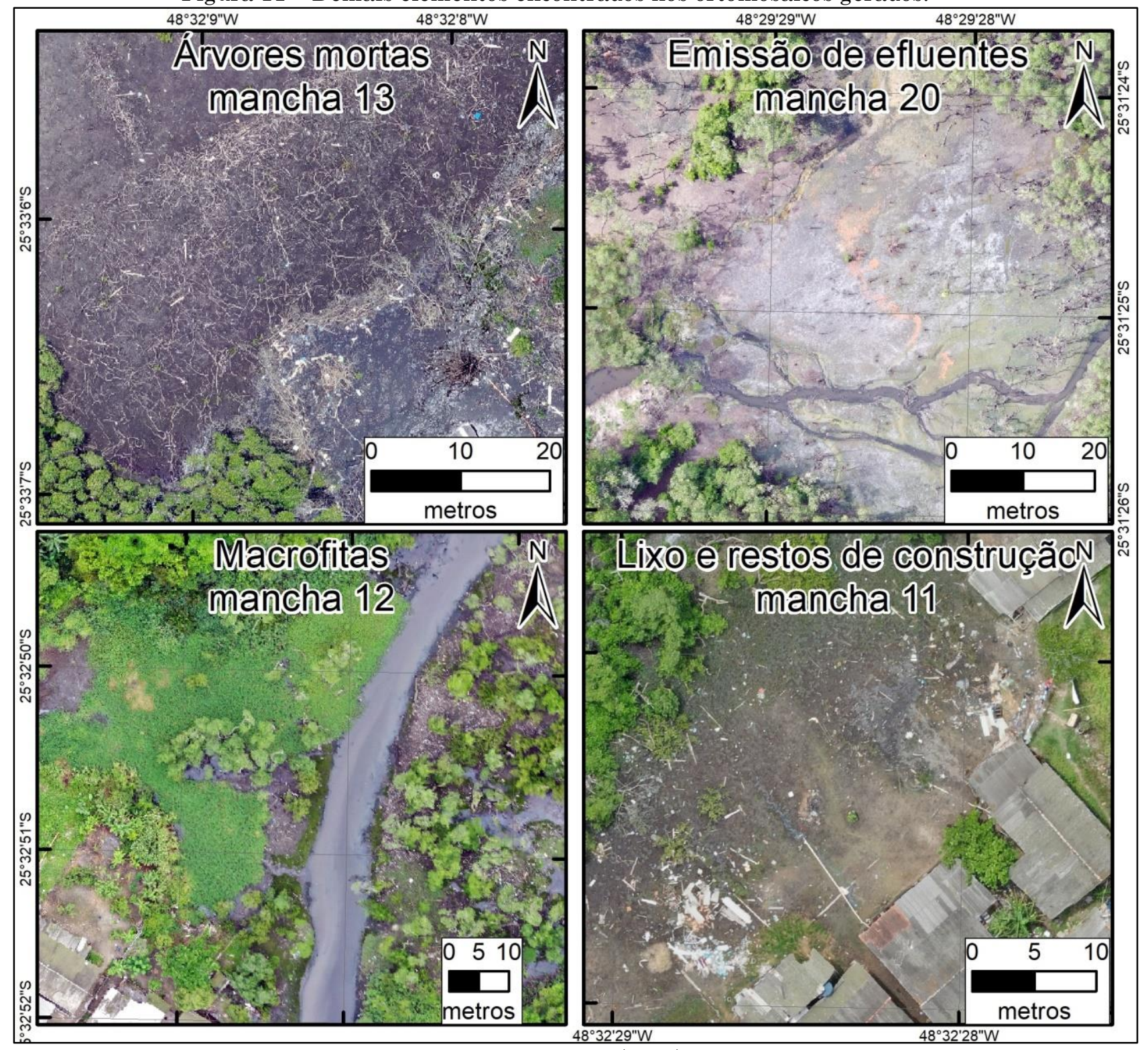

Fonte: Os autores (2021).

Cabe destacar que o nível de detalhamento alcançado pelos dados coletados por RPA não se restringe apenas a resolução espacial, mas se estende para a resolução temporal. Uma mesma mancha de manguezal pode ser imageada novamente em um intervalo de horas a minutos. Adicionalmente, existem câmeras multiespectrais para RPA que possibilitam a 
geração de índices de vegetação em alta resolução espacial. Tais características desta plataforma imageadora abrem um leque de possibilidades em estudos de manguezais, inclusive, permitindo estudos que antes eram inviáveis com dados de plataformas convencionais (imagens orbitais e fotografias aéreas).

\section{CONCLUSÃO}

A partir dos resultados da classificação supervisionada foi constatada a eficiência de dados coletados por RPA na identificação de áreas de solo exposto em manguezais em escala de detalhe. Estudos adicionais podem ser efetuados abordando a resposta espectral de outros alvos presentes neste ecossistema, como árvores mortas, áreas de solo exposto úmido e seco, lixo, restos de construção e até espécies no manguezal.

Os levantamentos realizados fornecem um diagnóstico da presença de solo exposto nos manguezais urbanos de Paranaguá, sendo possível uma regionalização desta situação em três grupos. $\mathrm{O}$ grupo $\mathrm{A}$, situado as margens do rio Emboguaçu, apresenta os maiores valores de solo exposto, merecendo atenção em ações de recuperação ambiental e ordenamento territorial.

Este estudo também serve como marco de análise da situação dos manguezais urbanos de Paranaguá, em função do nível de detalhamento alcançado. Os resultados obtidos podem ser comparados com levantamentos futuros, visando uma análise temporal e espacial de detalhe. Os mapas e dados geoespaciais gerados nesta pesquisa foram encaminhados à prefeitura de Paranaguá, podendo subsidiar análises no âmbito de instrumentos de planejamento municipal, como a revisão do Plano Diretor e elaboração do Plano de Saneamento Básico e do Plano de Regularização Fundiária, bem como em ações de vistoria e fiscalização.

\section{AGRADECIMENTOS}

O financiamento desta pesquisa se deu por meio de Termo de Ajuste Conduta (TAC) firmado entre empresa do litoral do Paraná, o Ministério Público do Paraná e a Universidade Federal do Paraná (UFPR), tendo o Laboratório de Geoprocessamento e Estudos Ambientais (LAGEAMB) como executor, com o apoio do
Laboratório de Biogeografia e Solos (LABS) e do Centro de Pesquisas Aplicadas em Geoinformação (CEPAG). Os autores agradecem as instituições citadas acima. Os autores também agradecem aos revisores deste artigo e ao editor da revista Sociedade \& Natureza, pelas críticas e sugestões ao longo do processo de publicação.

\section{REFERÊNCIAS}

AMARAL, F. G., CRUZ, C. B. M., DA CRUZ, C. L. Z., VIEGAS, V. S., DA SILVA, C. B., \& BASTOS, R. M. C. Ecologia da Paisagem e o Sensoriamento Remoto na investigação da dinâmica da Paisagem. In: ENANPEGE - Encontro Nacional da ANPEGE, XIII, São Paulo, 2019.

BRANDÃO, I. M.; GUIMARÃES, A. S.; TRAVASSOS, P. E. P. Ecologia de paisagem: uma análise multi-temporal dos manguezais urbanos do complexo de salgadinho, Olinda-PE. Anais... XIV Simpósio Brasileiro de Sensoriamento Remoto, Natal, Brasil, INPE, p.25-30. 2009.

BRASIL. Lei $\mathrm{n}^{\circ} 12.651$, de 25 de maio de 2012.

Diário Oficial da União, 2012. Disponível em: <http://www.planalto.gov.br/ccivil_03/_ato20112014/2012/lei/l12651.htm>. Acesso em: 12 ago. 2020.

CANEPARO, S. C. Manguezais de Paranaguá: uma análise da dinâmica espacial da ocupação antrópica - 1952-1996. 1999. 289 p. Tese (Doutorado em Geografia) - Universidade Federal do Paraná, Curitiba, 1999.

CANEPARO, S. C. ANÁLISE DA DINÂMICA ESPACIAL DA OCUPAÇÃO ANTRÓPICA EM PARANAGUÁ/PR (1952-1996), ATRAVÉS DO USO DE SISTEMA DE INFORMAÇÕES GEOGRÁFICAS. Raega. v. 4, p. 111-130, 2000. http://dx.doi.org/10.5380/raega.v4i0

CAO, J.; LENG, W.; LIU, K.; LIU, L.; HE, Z.; ZHU, Y. Object-based mangrove species classification using unmanned aerial vehicle hyperspectral images and digital surface models. Remote Sensing, v. $10, \quad$ n. $1, \quad$ p. $89,2018$. https://doi.org/10.3390/rs10010089

CELERI, M. J.; MENDES, L. E. T.; DE FIGUEIREDO LIMA, R. M. B.; DA ROCHA VASCONCELOS, T. A cidade, o mangue e os resíduos sólidos: estudo de caso do Manguezal Vinhais, São Luís-MA. Geografia em Atos (Online), v. 3, n. 10, p. 163-186, 2019. https://doi.org/10.35416/geoatos.v3i10.5710

DAYALATHA, W. K. V; ALI, S. K. M. The Use of Mangroves as a Source of Fire Wood: A SocioEconomic Study on Selected Mangroves in Southern Sri Lanka. Journal of Social Sciences and Humanities Review, v. 3, n. 3, p. 175-193 2018. http://doi.org/10.4038/jsshr.v3i3.14 
DSG, - DIRETORIA DO SERVIÇO GEOGRÁFICO. Especificação técnica para a aquisição de dados geoespaciais vetoriais (ETADGV). Ministério da Defesa, Exército Brasileiro, Departamento de Ciência e Tecnologia. Brasília-DF, 2a edição, v. 2, 2016. Disponível em: <http://www.geoportal.eb.mil.br/portal/index.ph p/inde2?id=140>. Acesso em: 13 ago. 2020.

DUGAN, P. J. Conservación de Humedales: un análisis de temas de actualidad y acciones necesarias. $1^{\mathrm{a}}$ ed. Gland: IUCN, 1992.

FERNANDES, R. T. V.; DE OLIVEIRA, J. F.; DE OLIVEIRA, J. C. D.; FERNANDES, R. T. V.; NASCIMENTO, L.; PINTO, A. R. M.; NOVAES, J. L. C. Impacto da carcinicultura no manguezal do rio das Conchas, Porto do Mangue, Rio Grande do Norte. Revista Sociedade \& Natureza, v. 30, n. 3, p. 64-84, 2018. https://doi.org/10.14393/SNv30n3-2018-4

GIRI, C.; OCHIENG, E.; TIESZEN, L. L.; ZHU, Z.; SINGH, A.; LOVELAND, T.; MASEK, J.; DUKE, N. Status and distribution of mangrove forests of the world using earth observation satellite data. Global Ecology and Biogeography, v. 20, n. 1, p. 154-159, 2011. https://doi.org/10.1111/j.14668238.2010.00584.x

HELD, A.; TICEHURST, C.; LYMBURNER, L.; WILLIAMS, N. High resolution mapping of tropical mangrove ecosystems using hyperspectral and radar remote sensing. International Journal of Remote Sensing, v. 24, n. $13, \quad$ p. 2739-2759, 2003. https://doi.org/10.1080/0143116031000066323

IAT - Instituto de Água e Terra. Geodados. 2016. Disponível em: <http://www.iat.pr.gov.br>. Acesso: Julho 08, 2021.

JIA, M.; ZHANG, Y.; WANG, Z.; SONG, K.; REN, C. Mapping the distribution of mangrove species in the Core Zone of Mai Po Marshes Nature Reserve, Hong Kong, using hyperspectral data and high-resolution data. International journal of applied earth observation and geoinformation, v. 33, p. 226-231, 2014. https://doi.org/10.1016/j.jag.2014.06.006

JONES, A. R.; SEGARAN, R. R.; CLARKE, K. D.; WAYCOTT, M.; GOH, W. S. H.; GILLANDERS, B. M. Estimating mangrove tree biomass and carbon content: a comparison of forest inventory techniques and drone imagery. Frontiers in Marine Science, 2020. https://doi.org/10.3389/fmars.2019.00784

KANNIAH, K. D.; SHEIKHI, A.; CRACKNELL, A. P.; GOH, H. C.; TAN, K. P.; HO, C. S.; RASLI, F. N. Satellite images for monitoring mangrove cover changes in a fast growing economic region in southern Peninsular Malaysia. Remote Sensing, v. 7, n. 11, p. 14360-14385, 2015. https://doi.org/10.3390/rs71114360

KENNISH, M. J. Encyclopedia of Estuaries. Encyclopedia of Earth Sciences Series. Springer, 2016.
KJERFVE, B.; LACERDA, L. D. Mangroves of Brazil. In: LACERDA, L. D. (Ed.). Conservation and sustainable utilization of mangrove forest in Latin America and Africa regions. Okinawa: ITTO/ISME, 1993., p. 272.

KRUMME, U.; GIARRIZZO, T.; PEREIRA, R.; DE JESUS, A. J. S.; SCHAUB, C.; SAINT-PAUL, U. Airborne synthetic-aperture radar (SAR) imaging to help assess impacts of stationary fishing gear on the north Brazilian mangrove coast. ICES Journal of Marine Science, v. 72, n. 3, p. 939-951, 2015. https://doi.org/10.1093/icesjms/fsu188

KUENZER, C.; BLUEMEL, A.; GEBHARDT, S.; QUOC, T. V.; DECH, S. Remote sensing of mangrove ecosystems: A review. Remote Sensing, v. 3, n. 5, p. 878-928, 2011. https://doi.org/10.3390/rs3050878

LANDIS, J. R.; KOCH, G. G. The measurement of observer agreement for categorical data. Biometrics, v. 33, n. 1, p. 159-174, 1977. https://doi.org/10.2307/2529310

LEAL, E. B.; DA SILVA JÚNIOR, S. L.; BORGES, A. C.; DOS SANTOS LIRA, O. V. Análise do processo de ocupação em área de mangue no bairro de São Miguel, no município de Maracanã/PA. Os Desafios da Geografia Física na Fronteira do Conhecimento, v. 1, p. 68046816, 2017.

LIMA, T. B. B.; SILVA, M. R. F.; CARVALHO, R. G. Pesca artesanal, carcinicultura e manguezal: perspectivas da lei 12.651/2012 e o uso de apicuns e salgados em Canguaretama/RN. Sociedade \& Natureza, v. 31, p. 1-20, 2019. https://doi.org/10.14393/SN-v31n1-2019-37481

MADI, A. P. L. M., BOEGER, M. R. T., LARCHER, L., PELOZO, A., SERENESKI, C., REISSMANN, C. B., \& PADIAL, A. A. Estrutura do componente de regeneração natural e arbóreo de dois manguezais no estado do Paraná. Ciência Florestal, v. 26, n. 1, p. 159-170, 2016. https://doi.org/10.5902/1980509821100

MAIA, R. C.; SILVA, K. N.; BENEVIDES, J. DE A. J.; AMORIM, V. G.; DE SOUSA, R. M. IMPACTOS AMBIENTAIS EM MANGUEZAIS NO CEARÁ: CAUSAS E CONMAIA, R. C. et al. IMPACTOS AMBIENTAIS EM MANGUEZAIS NO CEARÁ: CAUSAS E CONSEQUENNCIAS. Conexões-Ciência e Tecnologia, v. 13, n. 5, p. 6977 , 2019. https://doi.org/10.21439/conexoes.v13i5.1797

MALIK, A.; FENSHOLT, R.; MERTZ, O. Economic valuation of mangroves for comparison with commercial aquaculture in South Sulawesi, Indonesia. Forests, v. 6, n. 9, p. 3028-3044, 2015. https://doi.org/10.3390/f6093028

MATIAS, L.; SILVA, M. D. Monitoramento e análise da vegetação de manguezal no litoral sul de Alagoas. Journal of Environmental Analysis and Progress, v. 2, n. 3, p. 312-319, 2017. https://doi.org/10.24221/jeap.2.3.2017.1447.312319 
MILLER, J. E. D.; ZITER, C. D.; KOONTZ, M. J. Fieldwork in landscape ecology. 2020. https://doi.org/10.31219/osf.io/ybg9d

OLIVEIRA, R. G.; TOGNELLA, M. M. P. Processo de colonização do manguezal do Rio Tavares por análise da estrutura de diferentes bosques. Brazilian Journal of Aquatic Science and Technology, v. 18, n. 1, p. 9-18, 2014.

PAZ, O. L. S.; DAL PAI, M. O.; PAULA, E. V. Proposta metodológica para elaboração de base de dados geoespaciais como subsídio a estudos ambientais: aplicação em unidades de conservação do litoral norte do Paraná. Revista Brasileira de Geografia Física, v. 13, n. 02, p. 613-629, 2020. https://doi.org/10.26848/rbgf.v13.2.p613-629

PELOZO, A. Regeneração natural das espécies arbóreas dos manguezais do Paraná. Dissertação (Mestrado em Botânica) - Departamento de Ciências Biológicas, Universidade Federal do Paraná. Curitiba, Paraná, p. 63, 2012.

PERRIER, C. Analysis of the mangrove and chenier dynamics using drone imagery in Demak, Indonesia. Dissertação (Master in Marine Research) - Royal Netherlands Institute for Sea Research, Yerseke, 2019.

PINHEIRO, M. A. A.; TALAMONI, A. C. B. Educação Ambiental sobre Manguezais. São Vicente: UNESP, Instituto de Biociências, Câmpus do Litoral Paulista, 2018.

RUWAIMANA, M.; SATYANARAYANA, B.; OTERO, V.; MUSLIM, A. M. The advantages of using drones over space-borne imagery in the mapping of mangrove forests. PloS one, v. 13, n. 7 , 2018. https://doi.org/10.1371/journal.pone.0200288

SALEH, M. A. Assessment of mangrove vegetation on Abu Minqar Island of the Red Sea. Journal of Arid Environments, v. 68, n. 2, p. 331-336, 2007. https://doi.org/10.1016/j.jaridenv.2006.05.016

SALUM, R. B.; SOUZA-FILHO, P. W. M.; SIMARD, M.; SILVA, C. A.; FERNANDES, M. E. B.; COUGO, M. F.; DO NASCIMENTO JUNIOR, W.; ROGERS, K. Improving mangrove aboveground biomass estimates using LiDAR. Estuarine, Coastal and Shelf Science, p. 106585, 2020. https://doi.org/10.1016/j.ecss.2020.106585

SHAEFER-NOVELLI, Y. Manguezal: Ecossistema entre a terra e o mar. $1^{\circ}$ ed. São Paulo: Caribbean Ecological Research, 64p. 1995.

SCHAEFFER-NOVELLI, Y.; CINTRÓNMOLERO, G.; SOARES, M. L. G.; ROSA, T. Brazilian mangroves. Aquatic Ecosystem Health and Management, v. 3, p. 561-570, 2000. https://doi.org/10.1080/14634980008650693

SCHAEFFER-NOVELLI, Y., CINTRÓN, G., CUNHA-LIGNON, M.; COELHO-JR., C. A conceptual hierarchical framework for marine coastal management and conservation: a Januslike approach. Journal of Coastal Research, Special Issue 42:1-7, 2005.

SCHAEFFER-NOVELLI, Y. Sistema manguezal. Tese (Doutorado em Ciências Ambientais) Instituto de Energia e Ambiente, Universidade de São Paulo, São Paulo. 2016.

SEMUR - Secretaria Municipal de Urbanismo de Paranaguá. Ortoimagem da área urbana de Paranaguá. Paranaguá: SEMUR, 2010. Arquivo digital (matricial).

SOSMA - S.O.S. Mata Atlântica. 2021. Disponível em: https://www.sosma.org.br/causas/mataatlantica/.

VANNUCCI, M. Os manguezais e nós. São Paulo: Editora da Universidade de São Paulo, 2002. 244 p.

WANG, L.; JIA, M.; YIN, D.; TIAN, J. A review of remote sensing for mangrove forests: 1956-2018. Remote Sensing of Environment, v. 231, p. 111223

2019. https://doi.org/10.1016/j.rse.2019.111223

ZIMUDZI, E.; SANDERS, I.; ROLLINGS, N.; OMLIN, C. Segmenting mangrove ecosystems drone images using SLIC superpixels. Geocarto International, v. 34, n. 14, p. 1648-1662, 2019. https://doi.org/10.1080/10106049.2018.1497093

\section{CONTRIBUIÇÃO DOS AUTORES}

Otacílio Lopes de Souza da Paz: concebeu o estudo, desenvolveu a metodologia proposta, coletou e analisou os dados e redigiu o texto. Participou na escrita do projeto de pesquisa para aquisição de financiamento. Sidney Vincent de Paul Vikou: concebeu o estudo, participou da coleta de dados e contribuiu com o texto. Participou na escrita do projeto de pesquisa para aquisição de financiamento. Daiane Maria Pilatti: concebeu o estudo, participou da coleta de dados e contribuiu com o texto. Participou na escrita do projeto de pesquisa para aquisição de financiamento. Atuou na coordenação do projeto que este artigo é vinculado. Eduardo Vedor de Paula: concebeu o estudo e contribuiu com o texto. Responsável pela aquisição de financiamento. Atua na coordenação do laboratório onde esta pesquisa foi desenvolvida. Marianne de Oliveira: participou do processamento dos dados coletados e interpretação dos resultados obtidos. Contribuiu com o texto.

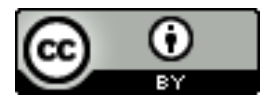

Este é um artigo de acesso aberto distribuído nos termos da Licença de Atribuição Creative Commons, que permite o uso irrestrito, distribuição e reprodução em qualquer meio, desde que o trabalho original seja devidamente citado. 